\title{
DO TEMPO [AO] PRESENTE: PARA LEMBRAR QUE A AIDS É UMA HISTÓRIA DE TODOS/AS NÓS!
}

\section{FROM TIME [TO THE] PRESENT: TO REMEMBER THAT AIDS IS A STORY FOR ALL OF US!}

Jair Zandoná ${ }^{1}$

JARDIM, Eduardo. A doença e o tempo: aids, uma história de todos nós. Rio de Janeiro: Bazar do Tempo, 2019.

Em uma época em que o impacto do Covid-19 no Brasil ainda tem sido mapeado, nada mais oportuno que retomar discussões importantes sobre como os significados de vírus estão sendo produzidos e ampliados. O imaginário dos “monstros invisíveis" (SANT’ANNA, 2020, on-line) do século XIX tem tomado outras proporções quando, em pleno século XXI, tivemos que aprender a lavar as mãos, cujo efeito fez com que se estreitasse a vigilância sobre saúde e tem, sobretudo, enfatizado as diferenças sociais evidenciadas pela crise pandêmica. Mas Eduardo Jardim, tal como o título de seu mais recente livro indica - A doença e o tempo: aids, uma história de todos nós - traz para a cena reflexões importantes sobre hiv/aids considerando aspectos históricos, sociais e culturais desde o momento em que esse vírus ainda era desconhecido até tomar forma e feições - equivocadamente definidas - de maneira a causar “danos à saúde pública [que] justificou a discriminação, sobretudo dos homossexuais" (JARDIM, 2019, p. 10), pois se lidava com uma doença incurável e, no imaginário coletivo, residia a pretensa compreensão na qual "poderia ficar confinada aos grupos de risco." (JARDIM, 2019, p. 10).

\footnotetext{
${ }^{1}$ Doutor em Literatura - UFSC, Pesquisador associado do Instituto de Estudos de Gênero (IEG/UFSC) e do Núcleo de Literatura Brasileira Atual - Estudos Feministas e Pós-Coloniais de Narrativas da Contemporaneidade (LITERATUAL/UFSC). e - mail: jzandona@gmail.com
} 


\section{Debates Insubmissos}

Revista

Doutor em Filosofia, Eduardo Jardim, interessado em compreender o contexto contemporâneo, organiza seu ensaio - cujo fio condutor é o tempo, ou, como nomeia o texto de abertura, "Uma vivência do tempo" - a partir da noção de que a "aids é uma doença que acontece no tempo" (JARDIM, 2019, p. 9). Mas se o cenário atual é diverso daquele experimentado no século passado, interessa ao filósofo saber se as perguntas que eram feitas no início da epidemia no Brasil e em outras partes do mundo ainda preocupam as novas gerações. Não por acaso, é a cronologia que marca sua narrativa desde a descoberta da aids no Brasil em 1983, os primeiros testes realizados em 1985, a distribuição do AZT dois anos depois e a implementação do coquetel passado mais de uma década a esse primeiro medicamento.

Em “a viagem" - o primeiro tempo do vírus -, Jardim constrói uma interessante cartografia do vírus ao apontar que sua propagação está intimamente relacionada aos efeitos do poder e da força coloniais, entre os séculos XIX e XX, visto que "não teria se espalhado como uma epidemia, não fossem as condições em que viviam os habitantes das colônias africanas" (JARDIM, 2019, p. 15), em especial do Congo. A precariedade na qual boa parte da população vivia, bem como a intensificação do trânsito de europeus com propósitos exploratórios, resultou na transformação social e demográfica. Como decorrência, contribuiu para que proliferasse a contaminação de enfermidades como a doença do sono, cujo tratamento era feito com seringas não descartáveis, causando muitas mortes. Em seu exercício da escrita, o autor recorre, nesse e em outros capítulos, a exemplos literários para situar suas análises. Com relação aos empreendimentos exploratórios, retoma a novela Coração das trevas (1902), de Joseph Conrad, e o romance de Mario Vargas Llosa, O sonho do celta (2010), os quais fazem referência à existência de uma doença que ainda era desconhecida. Ao situar o projeto colonial como responsável por propagar a aids, provocando um problema ecológico, motivo pelo qual seria produtivo realizar uma ecocrítica pós-colonialista do surgimento do hiv, as consequências são percebidas ainda hoje mesmo no pós-independência na medida que políticas públicas equivocadas causaram a morte de centenas de milhares de africanos e africanas (JARDIM, 2019, p. 19) -, analisa, então, os impactos da aids no Haiti, Estados Unidos e Brasil. 
A metáfora da viagem não é sem propósito em se tratando de epidemias/pandemias, visto que tempo e espaço estão na lógica da viagem. Nesse sentido, há a hipótese de que o vírus tenha sido levado para o país quando trabalhadores haitianos retornaram de missões de cooperação organizadas pela ONU e realizadas no Congo entre 1960 e 1970. O cenário de miséria que assolava os "dois lados do Atlântico" (JARDIM, 2019, p. 19) era semelhante, de maneira que ainda hoje a aids é um problema de saúde pública, agravado pelos efeitos do regime ditatorial. O contexto estadunidense para a aids mobiliza-se de modo distinto, pois grupos como o ACT UP (Aids Coalition to Unleash Power), criado em 1987, são cruciais nas estratégias de tratamento e prevenção. Considerando que naquele momento a população gay era a mais atingida - motivando especulações preconceituosas nas quais criticavam o comportamento dos homossexuais - (JARDIM, 2019, p. 23), as pessoas que na década anterior estavam engajadas no movimento de liberação sexual, uniram-se para enfrentar a doença. Além disso, pesquisas já estavam sendo feitas desde 1981 para identificar as formas de contaminação e estabelecer estratégias de prevenção, como campanhas que recomendavam a prática do sexo seguro.

Não por acaso não apenas nos EUA como em outros lugares do mundo defendeu-se o uso de preservativo - inventado na Idade Média para prevenção da sífilis -, mas que foi fortemente rechaçado pelos grupos conservadores. Ao passo que o movimento crescia, ações diretas e de impacto eram realizadas, como foi o caso do gigantesco tapete feito de retalhos representando os mortos em decorrência da aids e que foi estendido em frente ao Capitólio, em Washington, em 1987, ou, ainda, em 1991, por conta da Guerra do Golfo, a Estação Central de Nova York foi ocupada por ativistas que carregavam faixas dizendo "Lutem contra a aids, não contra os árabes" (JARDIM, 2019, p. 25). A força do ativismo no país alterou significativamente as condições das pessoas soropositivas - mesmo com a objeção das frentes conservadoras - quanto ao controle dos bancos de sangues, para as trocas de seringas dos usuários de drogas, aceleração no ritmo de produção e testagem de medicamentos e, também, houve a aprovação do senado para contribuir com o programa da ONU de ajuda aos países africanos. 


\section{Revista \\ Debates Insubmissos}

No Brasil, a aids foi mencionada pela imprensa pela primeira vez em 1981, sendo abordada, normalmente, de maneira preconceituosa e sensacionalista. Jardim retoma, sobre isso, a conhecida capa da revista Veja de 1989 na qual ilustra Cazuza já em estado avançado da doença. Os primeiros registros médicos no Brasil foram apresentados, ainda durante o período ditatorial, em um congresso médico em 1983 relatando o caso de dois homens que haviam visitado os EUA (JARDIM, 2019, p. 27). Como naquele momento não havia um movimento organizado dedicado em produzir materiais sobre as recentes descobertas que circulassem sem estarem atravessados por discursos preconceituosos, ser soropositivo implicaria sair do armário. Lidar com um contexto hostil, inclusive familiar, fez com que muitos homens morressem sem tratamento para evitar necessidade de revelarem sua orientação sexual. A Secretaria da Saúde do Estado de São Paulo, alinhada às ações progressistas da gestão de Franco Montoro (19831988), protagonizou ações de conscientização sobre a aids, como a produção de panfletos e materiais explicativos sobre a doença ${ }^{2}$.

Essas e outras iniciativas contribuíram para a definição do texto que nortearia a Constituição de 1988, a consequente criação do SUS e também definiu os rumos para o enfrentamento da aids no país. Tal configuração é importante porque além de situar a centralidade do poder do Estado, sinaliza as resistências que determinadas agências estatais lidaram com a aids e o pouco investimento de recursos financeiros era a, então, nova doença. Como desdobramentos da expansão da epidemia, se, num primeiro momento, a doença atingiu "homossexuais masculinos das classes média e alta, e moradores dos centros urbanos. Em seguida, houve a feminilização da doença [...] especialmente a partir da década de 1990 [...] [e] a pauperização da epidemia" (JARDIM, 2019, p. 31) ao atingir a população de periferia, bem como a sua interiorização para outras partes do país. Data de 1996 a lei que determina a distribuição gratuita da medicação necessária para todo o tratamento de soropositivo.

\footnotetext{
${ }^{2}$ A esse respeito, conferir, por exemplo, as orientações disponíveis no documento produzido pela Secretaria de Estado da Saúde, coordenadoria de Serviços Técnicos Especializados do Instituto de Saúde - Divisão de Dermatologia Sanitária encontrado no acervo do Somos: Grupo de Afirmação Homossexual/SP foi o primeiro grupo brasileiro engajado na causa e luta homossexual disponível no AEL/Unicamp (SOMOS PI 0.004 DOC.076, coleção do Grupo Somos, pasta 28).
} 
Se a história da doença se alinha às descobertas médicas, Jardim encerra a seção apresentando dados atuais sobre o cenário de transmissão do vírus a partir de coleta de dados feita em 2016 em 12 das maiores cidades brasileiras, cujos valores dobraram ou triplicaram a depender da faixa etária. Entre as hipóteses, menciona:

Houve cortes em programas de prevenção e testagem, por causa da diminuição de
recursos. Ao mesmo tempo, observou-se uma mudança dos hábitos sexuais, que
resultou indiretamente do avanço da medicina e do aperfeiçoamento dos
medicamentos. [...] também alerta para a influência no governo de grupos
conservadores de defendem agendas reacionárias em assuntos de gênero exexualidade
(JARDIM, 2019, p. 35).

Em "peste, aids e castigo" - o segundo tempo do vírus - Eduardo Jardim, ao aproximar a concepção de peste como castigo divino, recorre a Um diário do ano da peste, de Daniel Defoe, cuja narrativa está situada na grande epidemia de 1665 em Londres (MARKENDORF; FELIPPE, 2018, p. 316) e que teria sido enviada por Deus "possivelmente por causa da adoção dos novos e reprováveis costumes." (JARDIM, 2019, p. 40). De maneira semelhante, a aids foi considerada uma penalização divina em decorrência das manifestações políticas e mudanças de costumes ocorridas nas décadas de 1960 e 1970. No Brasil, os movimentos feminista, lésbico, homossexual, travesti, negro, indígena, ecologista e outros foram cruciais para estabelecer modos de resistência contra a ditadura (WOLFF; ZANDONÁ; MELLO, 2019). No cenário estadunidense, a expansão dos casos de aids ocorreu ao mesmo tempo em que houve o fortalecimento de grupos conservadores, de maneira que os discursos recorrentes sustentavam que a doença seria "resultado da depravação e da decadência dos costumes" (JARDIM, 2019, p. 40), o que não foi diferente no Brasil. Nessa perspectiva, tanto a peste quanto a aids seriam "castigos enviados por Deus para corrigir os pecados dos homens" (JARDIM, 2019, p. 44). Se a peste, retomando Daniel Defoe e Albert Camus, assolou comunidades inteiras, a aids atacaria alguns setores da população, os que se enquadravam nos grupos de risco.

Se a princípio teve o propósito estatístico de indicar a probabilidade de manifestação de uma doença ou outro fator relacionado à saúde de uma população, com a aids a noção de grupo de risco deixou de significar apenas o cociente entre o número de casos positivos e a ocorrência de casos possíveis "e passou a designar entidades culturalmente definidas, como os homossexuais ou os usuários de drogas injetáveis.” (JARDIM, 2019, p. 44). As pessoas assim 
definidas deixaram de ser consideradas como pertencentes ao grupo de risco e passaram a ser consideradas "um perigo para o resto da população" (JARDIM, 2019, p. 44).

Essa afirmação do filósofo é importante porque as políticas públicas elaboradas a partir dessa noção de grupo de risco fez com que programas específicos fossem aplicados, desconsiderando o restante da população. Conforme aponta, "quando a epidemia se alastrou e se tornou um problema para todos, as providências para contê-la precisaram ser improvisadas às pressas. Isso afetou especialmente as mulheres, as mais atingidas no início dos anos 1990" (JARDIM, 2019, p. 45). As descobertas recentes indicavam que a transmissão do vírus poderia ocorrer através de relações sexuais, pelo sangue e de mãe para filho/a (durante a gestação, o parto ou a amamentação). Essas ponderações indicam algumas das consequências funestas da noção de grupo de risco e que reforça(ra)m práticas discriminatórias e preconceituosas sobre a aids (a terceira epidemia, ao retomar a expressão de Jonathan Mann), bem como motivou iniciativas de segregação praticadas em Cuba, por exemplo, ou práticas negacionistas como as que aconteceram na África do Sul (motivadas pelo trabalho de Peter Duesberg que, em 1988, afirmou que o hiv não é causa da aids ${ }^{3}$ ) (JARDIM, 2019, p. 46-47).

Com a alteração do perfil epidemiológico da aids, afirma Eduardo Jardim (2019, p. 48), a doença não se restringe a recortes espaciais ou a um ambiente, mas "que acontece no tempo" - tópico do terceiro tempo do livro: "aids e o tempo". Na medida que a aids passa a ser tema ou inspiração de escritores/as, cineastas e artistas, também motivou a pesquisa sociológica o ensaio e o depoimento pessoal, tal como os trabalhos de Michael Pollak, Susan Sontag e Hervé Guibert.

Nesse sentido, a importância do trabalho de Pollak está no fato de que o pesquisador pode vivenciar as alterações de comportamento e práticas sexuais devido à expansão da doença. Sontag abordou o tema da aids tanto na ficção quanto em seu trabalho ensaístico. No seu conhecido Aids e suas metáforas, a autora elabora uma crítica contundente sobre a "verdadeira

\footnotetext{
${ }^{3}$ Ver, por exemplo, DUESBERG, Peter. HIV não é a causa da AIDS. Rev. Latinoam. Psicopatol. Fundam., São Paulo, v. 11, n. 1, p. 98-104, 2008 e originalmente publicado na revista Science, New Series, v. 242, n. 4865, p. 514-517, 29 jul. 1988
} 
guerra cultural movida pelos neoconservadores com a chegada da aids." (JARDIM, 2019, p. 57). Além disso, também comenta as implicações que a onda libertadora dos anos anteriores, somada aos avanços na medicina, conforme Jardim (2019, p. 57), "favoreceu uma permissividade sexual que estaria associada ao consumismo das sociedades capitalistas." Nesse livro, Sontag define a aids como doença do tempo. Ao passo que o câncer se alastra pelo corpo por meio de metástases e sua evolução pode ser espacialmente percebida, "a aids se desenvolve por etapas até a morte do doente." (JARDIM, 2019, p. 58). Em outras palavras, "a aids é a terceira fase de um processo, quando as doenças oportunistas atingem o organismo desprotegido do ponto de vista imunológico.” (JARDIM, 2019, p. 58). Daí porque o ritmo de evolução da própria doença fez com que a passagem do tempo fosse compreendida de maneiras diversas. A obra de Guibert insere-se na produção de literatura autobiográfica sobre a descoberta de que era soropositivo e de como lhe acende a esperança de poder prolongar a vida - na expectativa de descobertas científicas e de criação de uma vacina contra o vírus. Quanto ao Brasil, entre os exemplos de Jardim dois são bastante conhecidos na história da aids no país: além de se referir à produção literária de Caio Fernando Abreu, menciona o ativismo de Herbert Daniel que atuou no movimento de esquerda durante o período ditatorial e que tomou outros rumos quando, em 1989, foi diagnosticado com hiv, registrando em livro essa experiência. Ficou conhecido nacional e internacionalmente por defender as pessoas soropositivas e por suas críticas à falta de políticas públicas e também à maneira como os meios de comunicação abordavam a doença - sempre associando à homossexualidade (GREEN, 2018).

O breve mapeamento da cena literária brasileira feita por Eduardo Jardim reforça a noção do tempo intensificada pela morte. Alterada a própria substância do tempo, argumenta que "[m]esmo guardando seu caráter fugidio, a vivência do presente se intensifica." (JARDIM, 2019, p. 65). Ao retomar Octavio Paz quanto a essa questão, concorda que a tentativa de capturar o tempo é sempre mal sucedida, pois o tempo verdadeiro está no presente, na presença (JARDIM, 2019, p. 65). Nesse sentido, a aids tem obrigado as pessoas a compreenderem a própria mortandade e a "possibilidade de se reconsiderar o valor da vida" (JARDIM, 2019, p. 66), sentido enfatizado no breve epílogo: "ainda estamos aqui”. 
As contribuições de Jardim entrecruzando aids e tempo são importantes na medida que situam a própria doença - e sua propagação - no tempo, as invisibilidades que os debates e a precarização de ações de políticas públicas têm (re)configurado o cenário atual. O tratamento de pessoas soropositivas tem ampliado significativamente a expectativa de vida e abordar aids e velhice, bem como o uso do PrEP (Profilaxia Pré-Exposição), pode(ria)m contribuir para as perguntas iniciais feitas pelo autor para "dar conta desse novo contexto" (JARDIM, 2019, p. 1), o qual pode, ainda, ser alterado por conta dos significados socialmente incorporados com o Codiv-19 para vírus, tratamento e (o) presente - o terceiro tempo do/s vírus e das vidas.

\section{REFERÊNCIAS}

GREEN, James. Revolucionário e Gay: A vida extraordinária de Herbert Daniel. Trad. de Marília Sette Câmara. Rio de Janeiro: Civilização Brasileira, 2018.

JARDIM, Eduardo. A doença e o tempo: aids, uma história de todos nós. Rio de Janeiro: Bazar do Tempo, 2019.

MARKENDORF, Marcio; FELIPPE, Renata de. Ficções da peste: esboço para um estudo do imaginário ficcional das doenças. Scripta Uniandrade, v. 16, n. 1, p. 309-331. 2018. Disponível em: https://uniandrade.br/revistauniandrade/index.php/ScriptaUniandrade/article/view/872/828. Acesso em: 30/03/2020.

SANT'ANNA, Denise Bernuzzi de. Lavar as mãos, descolonizar o futuro. \#PandemiaCrítica, n. 006, N1-Edições, São Paulo, 26 de março de 2020. Disponível em: https://n1edicoes.org/006. Acesso em: 30/03/2020.

WOLFF, Cristina S.; ZANDONÁ, Jair; MELLO, Soraia C. (orgs.). Mulheres de Luta: feminismo e esquerdas no Brasil (1964-1985). Curitiba: Appris, 2019.

Submetido em: 02/04/2020

Aprovado em: 01/06/2020 